\title{
Psychosocial risk and management of physical diseases
}

\author{
Neil Schneiderman ${ }^{1}$ (D) Roger C. McIntosh ${ }^{1} \cdot$ Michael H. Antoni $^{1}$
}

Received: June 18, 2018/Accepted: December 18, 2018/Published online: January 10, 2019

(C) Springer Science+Business Media, LLC, part of Springer Nature 2019

\begin{abstract}
During the 40 years since the Yale conference on Behavioral Medicine and the founding of the Journal of Behavioral Medicine considerable progress has been made in understanding the role of psychosocial risk and management of physical diseases. We here describe the development of these fundamental concepts from early research on stress through studies of the Type A behavior pattern to more contemporary approaches to the relationship between psychosocial risks and benefits in relation to disease processes. This includes the relationship of psychosocial risk to cancers, cardiovascular diseases (CVD), cardiometabolic disorders, Human Immunodeficiency Virus (HIV)/Acquired Human Immune Deficiency Syndrome. During the past 40 years the effects of prolonged distress responses in the pathogenesis of some cancers and CVD have been well-established and modifiable behavioral, cognitive and social factors have been shown to produce favorable outcome components in the management of such diseases as breast cancer, coronary heart disease and HIV.
\end{abstract}

Keywords Stress responses - Psychosocial risk - Chronic diseases - Cancer - Cardiovascular disease - HIV/AIDS

Neil Schneiderman

nschneid@miami.edu

Roger C. McIntosh

r.mcintosh@miami.edu

Michael H. Antoni

mantoni@miami.edu

1 Health Division, Department of Psychology, University of Miami, 5665 Ponce de Leon Boulevard, Coral Gables, FL 33124, USA

\section{Introduction}

As early as 1865 , Bernard (1865-1965) pointed out that the maintenance of life depends upon keeping our internal milieu constant in the face of a changing environment, which Cannon later termed "homeostasis". Selye later used the term stress to indicate the effects of things that threaten homeostasis. Although stress responses evolved as adaptive processes, Selye (1956) pointed out that severe, prolonged stress responses can lead to tissue damage and disease. Based upon the appraisal of perceived threat, humans and other animals invoke coping responses (Lazarus \& Folkman, 1984). Thus, when fight or flight appears feasible, mammals tend to show autonomic and hormonal activities that maximize the possibility for muscular exertion (Cannon, 1929). In contrast, during aversive situations in which an active coping response is not available, mammals engage in a vigilance response that involves sympathetic nervous system (SNS) arousal accompanied by an active inhibition of movement and the shunting of blood away from the body periphery (Adams et al., 1968). The extent to which various situations elicit different patterns of biologic responses is called situational stereotypy (Lacey, 1967). Although diverse situations tend to elicit different patterns of stress responses, there are also individual differences in stress responses to the same situation, which has been termed response stereotypy (Lacey \& Lacey, 1958).

Because evolution has provided mammals with reasonably effective homeostatic mechanisms such as the baroreceptor reflex for dealing with short term stressors, such stressors typically do not impose a health burden. Conversely, if threat is chronic and persistent, particularly in older or unhealthy individuals, the long-term effects of stress responses may damage health (Schneiderman, 1983). 
This is particularly the case in humans, because our high capacity for symbolic thought may elicit persistent stress responses to a broad range of living conditions.

The purpose of this paper is to provide salient examples of how progress has been made during the past 40 years relating psychosocial risks and management to multiple chronic diseases. Because some of the early biobehavioral research involving psychosocial risk focused on its antecedents, we will begin with a discussion of lifestyle interventions in persons at elevated CVD risk. This will be followed by a brief description of psychosocial/behavioral interventions that have been developed in response to major adverse coronary events, and a discussion of underlying pathogenic mechanisms involving stress, the social environment and atherosclerosis, which are important precursors of CVD.

Another important disease in which psychosocial risk and behavioral management have played important roles has been Human Immunodeficiency Virus (HIV)/Acquired Human Immunodeficiency Syndrome (AIDS). Within the past quarter century we have seen psychosocial risk and management of HIV/AIDS go from palliative concerns to chronic disease management. The improved management of HIV/AIDS in the past two decades has left an unfortunate byproduct since CVD has become the leading cause of mortality in these patients (Islam et al., 2012; Mottillo et al., 2010). This has led to growing interest in studying psychosocial risk factors for CVD progression in these patients.

Although psychosocial risk and behavioral management have played important roles in research into CVD and HIV/ AIDS, psychosocial risk and behavioral management have arguably played as important a role in research into psychological adaptations to various cancers. Psychosocial risk factors (e.g., distress, negative affect, depressive symptoms) have been associated with physiological processes related to poor clinical outcomes (Antoni, 2013; Lutgendorf et al., 2010). Conversely, there is some evidence from major randomized clinical trials (RCT) involving cognitive behavioral therapy (CBT)-based psychosocial interventions in non-metastatic breast cancer patients that show improved adaptation, cellular immune and inflammatory processes, better disease course and better mortality rate across an 11-year median follow-up period (Andersen et al., 2008; Stagl et al., 2015). Based on research evidence it appears clear that psychosocial stressors can have adverse effects on CVD, HIV and cancer risk and that carefully designed behavioral intervention studies can improve health outcomes in these same chronic diseases. We begin our discussion with an examination of psychosocial risk and lifestyle interventions related to CVD.

\section{Cardiovascular disease and psychosocial risk}

\section{Lifestyle interventions in persons at high risk}

Type 2 diabetes mellitus is a major risk factor for coronary heart disease (CHD) in both men and women (AHA, 2010). People with diabetes have at least twice the risk of developing CHD than people without diabetes, and equal to that of persons who have had a previous myocardial infarction (Haffner et al., 1998). Two major RCT's were therefore conducted to determine whether lifestyle interventions targeting weight loss and an increase in physical activity could reduce the incidence of diabetes in persons at high risk for developing Type 2 diabetes (Knowler et al., 2002; Tuomilehto et al., 2001). After 4 years the cumulative incidence of diabetes in the Tuomilehto et al., 2001 Finish Diabetes Prevention Study was significantly lower in the intervention group compared to the control group. In the United States, the Diabetes Research Group (Knowler et al., 2002) randomly assigned pre-diabetic persons with elevated fasting and post-glucose-load plasma glucose concentrations to either a placebo, metformin (an anti-hyperglycemic agent) or lifestyle intervention group. After an average of 2.8 years, the lifestyle intervention reduced the incidence of diabetes by $58 \%$, whereas metformin reduced the incidence by $31 \%$ compared to the placebo control group.

Based on the success of the Diabetes Prevention Research Program and the Finnish Diabetes Prevention Trial, the Look AHEAD (Action for Health in Diabetes) RCT compared the effects of an intensive lifestyle (diet, exercise) intervention versus a diabetes support and education control group on major CHD events in overweight or obese participants with Type 2 diabetes (Wing et al., 2010). After 4 years, intervention participants showed greater improvement than control participants in terms of weight loss, fitness, hemoglobin A1c, systolic blood pressure and high-density and low-density lipoprotein cholesterol than control participants. However, after a median follow-up of 9.6 years, the incidence of cardiovascular events was not reduced in the intensive lifestyle intervention group relative to the control group although weight loss remained greater in the intensive lifestyle intervention group throughout the study (Wing et al., 2013). Although Look AHEAD demonstrated that overweight or obese adults with Type 2 diabetes can lose weight and maintain modest weight loss over a 10-year period, the lack of significant difference in the rates of cardiovascular events between groups has not been fully explained. One possibility is that the study may have been over-controlled insofar as both groups received comprehensive medical management. Thus, for example, the educational sessions 
in the control group and increased use of statins compared with the intervention group may have lessened the health differences between groups. Another possibility to consider is that the amount of weight loss between conditions, that included a differential of only $2.5 \%$ at the end, was too small to account for differences in clinical outcomes.

\section{Psychosocial interventions after major adverse coronary events}

Three relatively large-scale RCTs concentrating on lifestyle interventions after major adverse coronary events showed positive results in terms of morbidity or mortality in the lifestyle intervention group (Friedman et al., 1986; Gulliksson et al., 2011; Orth-Gomér et al., 2009). In contrast, 3 other relatively large-scale trials reported null results (Berkman et al., 2003; Frasure-Smith et al., 1997; Jones \& West, 1996). The Recurrent Coronary Prevention Project (RCPP) conducted by Friedman et al. (1986) randomized 862 post-MI patients in the ratio of 2:1 into a psychosocial-behavioral condition or a health education control condition. Patients in the psychosocial intervention condition received the same risk factor reduction information as those in the control condition, but also had relaxation training to decrease behavioral arousal as well as group based cognitive behavior therapy intended to decrease Type A behaviors (i.e., hostility, impatience, time urgency). The intervention participants, who attended both the cardiac counseling (control) sessions as well as the psychosocial-behavioral sessions, participated in a mean of 38 sessions $(61 \%)$ over 4.5 years, whereas control participants attended a mean of 25 sessions (76\%) during the same time period. Rate of recurrent myocardial infarction (MI) was significantly lower in the intervention (6.6\%) than in the control (17.2\%) condition. Compared to the control condition, intervention participants also revealed significant reductions in hostility, impatience, time urgency and depressed mood (Mendes de Leon et al., 1991).

The second major RCT reporting a positive outcome was the Stockholm Women's Intervention Trial for Coronary Heart Disease (SWITCHD), which was conducted on women who had suffered a major adverse coronary event, primarily an MI (Orth-Gomér et al., 2009). This trial randomized 237 women into either a group-based cognitive behavior therapy program or into usual care and followed them for a mean duration of 7.1 years. Content of the intervention focused on women's specific psychosocial risk profile, controlling behavioral risk factors, attenuating negative emotions, developing coping skills, reducing stress and improving social support. The intervention was provided during 20 sessions over the course of a year. Three quarters of the women in the intervention arm attended 15-20 sessions. From randomization until the end of follow-up (mean duration 7.1 years) the intervention compared with the control group showed an almost threefold protective effect on mortality rate (OR 0.33 ; 95\% CI $0.1-.74)$.

The third major RCT that provided a psychosocial-behavioral intervention and reported a positive outcome was the Secondary Prevention in Uppsala Primary Health Care Project (SUPRIM), which was conducted on women and men in Sweden who had suffered a major adverse coronary event (Gullikesson et al., 2011). The patients in the intervention condition were run in same sex groups. Patients received either usual care or traditional (usual) care plus a cognitive behavior therapy intervention highly similar to that conducted by Orth-Gomér et al. (2009). During a mean follow-up period of 7.8 years the intervention group had $45 \%$ fewer recurrent acute MIs than the control group (OR 0.55 ; $95 \%$ CI $0.36-0.85$ ).

In contrast to the psychosocial lifestyle intervention studies that provided positive results after a major adverse coronary event, Jones and West (1996) randomized 2328 post-MI patients into either an intervention condition receiving 7 weekly counseling, relaxation and stress-management sessions or into a usual care condition. According to Jones and West, $25 \%$ of the randomized participants did not attend any sessions. Based upon the published paper, it appears that many of the no-shows may never have agreed to participate in the trial, but were included in the "intentto-treat" analysis. Data were not provided on how many sessions were attended by other participants. The investigators found no significant differences within or between groups in reported anxiety and depression at baseline and 6 months, indicating that although attempts to elicit changes in these variables were secondary objectives of the trial, the psychosocial intervention was ineffective. Finally, the investigators found no differences between conditions in terms of recurrent MI mortality or other clinical complications.

In another psychosocial-behavioral intervention study, Frasure-Smith et al. (1997) randomized 1376 post-MI men and women into an intervention program or a usual care condition for a year in the Montreal Heart Attack Readjustment Trial (M-HART). A week after hospital discharge for the initial MI a research assistant telephoned each intervention participant and then monthly after that. The assistant administered a 20-item General Health Questionnaire that assesses psychological distress (Goldberg, 1972). If a patient scored 5 or higher on the scale or was readmitted to the hospital, the research assistant contacted the nurse responsible for that patient. The nurse then arranged to visit the patient as soon as possible. During the initial 1-h visit, the nurse evaluated the patient's psychosocial difficulties, needs and cardiac status. Immediate needs were addressed, and if the patient agreed, the nurse 
scheduled a second visit within a month. Further intervention visits continued as required until the project team decided that further contact was not needed. Approximately $75 \%$ of intervention condition participants received five to six 1-h nursing visits. The program had no discernible influence on psychological outcomes (e.g., depressive symptoms anxiety, anger or perceived social support) between conditions nor upon mortality. Intervention treated women, however showed marginally greater all-cause mortality (10.3\% intervention vs. $5.4 \%$ usual care, $p=0.051$ ) suggesting that the intervention may have been harmful to women. The reasons for this marginal finding are speculative.

The third major RCT with a null result that examined the effects of psychosocial-behavioral treatment in post-MI patients was the Enhancing Recovery in Coronary Heart Disease (ENRICHD) Trial that randomized 2481 post-MI patients (44\% women; $34 \%$ racial- or ethnic-minority participants) into a cognitive-behavioral intervention condition or into usual care (Berkman et al., 2003).

The goal of ENRICHD was to determine whether soon after MI in patients who were clinically depressed and/or had low perceived social support, cognitive-behavioral treatment for the depression and/or low social support could reduce the combined endpoint of recurrent MI and/or mortality. Cognitive-behavioral therapy was initiated at the median of 17 days after the index MI for a median of 11 individual sessions throughout 6 months. The major finding in ENRICHD was that after an average follow-up of 2.4 years, there was no significant differences in event-free survival between usual care $(75.9 \%)$ and the psychosocial intervention $(75.9 \%)$. The intervention, however, did produce a modest decrease in depression and feelings of low social support.

Because ENRICHD enrolled large numbers of women and minority participants, it was possible to conduct a post hoc secondary analysis examining the outcome of sex by race/ethnicity subgroups (Schneiderman et al., 2004). All of the participants were examined in a $2 \times 2$ factorial design with one dimension divided by men and women and the other dimension divided by majority Whites and minorities. Analyses indicated that among White men, those in the intervention group had both lower cardiac mortality and nonfatal MI; whereas, the differences between the intervention and control conditions were not significant among either minority men or White or minority women. Although the results of the re-analysis of the ENRICHD data are exploratory, they raise the issue of the extent to which interventions are culturally appropriate. Recall that in M-HART (Frasure-Smith et al., 1997) women, but not men may have been harmed by the intervention. Based on such concerns, SWITCHD (Orth-Gomér et al., 2009) and SUPRIM (Gullikesson et al., 2011) were conducted on same-sex groups and specifically addressed issues relevant to women or men. It remains speculative that differences in gender issues accounted for the differences in biomedical outcomes between ENRICHD versus SWITCHD and SUPRIM, but the differences in results suggest that attention to gender as well as other cultural factors need to be considered in future clinical trials.

\section{Exercise training in patients with chronic heart failure}

Substantial evidence exists that moderate regular exercise is cardioprotective in most people (Lavie et al., 2001). However, monitoring during exercise is indicated in CHD patients at moderate to high risk (e.g., significant left ventricular dysfunction). Heart failure, for example, is associated with increased morbidity and mortality, which is exacerbated when accompanied by major depression (Blumenthal et al., 2012). In the Heart Failure-A Controlled Trial Investigating Outcomes of Exercise Training (HF-Action), Blumenthal and colleagues conducted an RCT involving 2322 stable heart failure patients in the U.S., Canada and France. After 30 months of follow-up, 789 patients $(68 \%)$ died or were hospitalized in the usual care group compared with $759(66 \%)$ in the aerobic exercise group OR $0.89 ; 95 \%$ CI $0.81-0.99(p=.03)$. The aerobic exercise group revealed significantly lower mean Beck Depression Inventory-II scores at 3 months ( $p=.002)$ and at 12 months $(p=.01)$ than the usual care control group. Thus, compared with the control group, the exercise training group showed a modest reduction in depressive symptoms and composite death/or hospitalization outcome.

\section{Stress, social environment, neurocognitive processes and atherosclerosis}

The relationships between psychosocial stress and CVD risk have been explored extensively during the past 40 years. In addition to a large number of studies describing the association in humans, an impressive body of work by Clarkson, Kaplan, Manuck, Adams and their collaborators have successfully demonstrated a causal link between social hostility and coronary artery atherosclerosis in a cholesterol-fed ( $40 \%$ of calories from fat) cynomolgus monkey model of CVD (e.g., Clarkson et al., 1987). Cynomolgus macaques are highly social animals that live in tightly knit groups having well-developed networks of affiliation and clearly defined social status hierarchies. Introduction of strangers into these social groups provides a threat to existing relationships and is accompanied by intense fighting as animals attempt to re-establish social relationships (Manuck et al., 1986). The experimental 
approach to studying this disruption is to have groups of 4-6 animals living together. Once status hierarchies are established, a stable environment is created by maintaining the housing arrangements intact. Conversely, a stressful environment can be created by periodically reorganizing the membership of existing groups. In studies carried out in male animals, high status, dominant animals living in unstable social groups developed significantly more coronary atherosclerosis than less dominant animals housed in either stable or unstable conditions (Kaplan et al., 1983). The investigators further found that SNS activation in response to the psychosocial stress of social reorganization was associated with increased atherosclerosis (Manuck et al., 1983) and that blocking SNS activity with the nonspecific beta-adrenoceptor antagonist propranolol protected dominant male monkeys from developing increased atherosclerosis (Kaplan et al., 1987).

Other studies using the cholesterol-fed cynomolgus monkey have explicated how psychosocial factors can lead to increased atherosclerosis in females. These studies have shown that subordination is associated with hypercortisolism, ovarian dysfunction and, increased coronary artery atherosclerosis (Clarkson et al., 1989). Social isolation also influences the progression of atherosclerosis in cholesterolfed females, through increased SNS activation as indexed by elevated resting heart rate (Watson et al., 1998).

While studies in cynomolgus monkeys have demonstrated that disruption of the social environment or dominance hierarchy can promote coronary artery atherosclerosis, studies in the Watanabe heritable hyperlipidemic rabbit have shown that manipulation of the social environment can dramatically influence the progression of atherosclerosis. Briefly, the Watanabe heritable hyperlipidemic rabbit is an inbred strain that exhibits profound hypercholesterolemia, severely elevated plasma LDL cholesterol levels and hypertriglyceridemia from birth due to a single gene mutation. This leads to aberrant LDL receptors (Buja et al., 1983) similar to those observed in familial hypercholesterolemia, which affects approximately $0.2 \%$ of the human population (Buja et al., 1990). The Watanabe rabbits develop severe atherosclerosis within the first 6 months of life. In an initial behavioral study conducted on the Watanabe rabbit, McCabe et al. (2002) assigned 3 month old male animals to 1 of 3 social/ behavioral groups: an unstable group, in which unfamiliar rabbits were paired for $4 \mathrm{~h}$ daily, with the pairing switched each week; a stable group in which littermates were paired daily for the entire study; and an individually caged group, in which animals did not have physical contact with other rabbits. The social conditions were maintained for 4 months and the study terminated when the animals were 7 months old. Over the course of the study, the stable animals exhibited significantly more affiliative social behavior and less agonistic behavior than the unstable group. The stable group also developed less than half the amount of aortic atherosclerosis than the unstable or individually caged groups. Thus, the major finding of the study was that a stable social environment characterized by increased affiliative behavior and little agonistic behavior can slow the progression of atherosclerosis in relation to unstable social conditions or individual cages. Subsequent studies indicated that microdialysis of oxytocin from the paraventricular nucleus of the hypothalamus resulted in significant increases in oxytocin in the microdialysate of animals in a stable group compared with individually caged animals or members of an unstable group and this was associated with lower levels of plasma catecholamines (Paredes et al., 2006). Still other studies have shown that incubating human aortic vascular cells with physiological levels of oxytocin can attenuate vascular oxidative stress and inflammation (Szeto et al., 2008).

In addition to the animal studies relating stress, social environment and atherosclerosis, studies conducted on humans have shown that subclinical vascular disease is also associated with cognitive impairment in humans (Gorelick et al., 2011). Thus, biomarkers of atherosclerosis have been associated with impaired executive function and working memory (Smith et al., 2007) as well as magnetic imaging markers of microvascular dysfunction (Smith et al., 2010). Subsequently, Smith et al. (2018) found that greater microvascular dysfunction in the form of impaired hyperemic velocity during flow mediated dilation of the brachial artery in older adults with major depressive disorder was associated with poorer neurocognition, particularly working memory and executive function. The links among psychological functioning, brain activity and cardiovascular risk are likely to become increasingly important in the study of psychosocial risk and the management of physical diseases.

\section{Psychosocial risk in human immunodeficiency virus (HIV)}

Major research advances in our understanding of psychosocial risk factors and disease management in persons living with HIV or AIDS (PLHA) have largely occurred during the past 30 years. Most of the advances have occurred in conjunction with highly active anti-retroviral therapy (HAART). In the decade preceding the widespread availability of HAART the primary psychosocial research interests related to survival and palliative care. During the decade that introduced HAART the psychosocial emphases were on suppression of the virus and factors related to HAART adherence. In the past 10 years research addressing psychosocial risk in PLHA have also dealt with syndemic issues associated with advancing age and disease 
comorbidity with the greatest focus on CVD outcomes in this population.

\section{Psychosocial correlates of cell-mediated immunity in the survival era of HIV/AIDS}

In the beginning of the HIV epidemic CD4+ T-lymphocyte cell count was the immune marker of focus as it was most closely linked to the clinical consequences of HIV infection (i.e., progression to AIDS-defining illness and AIDSrelated mortality). Prior to the HIV epidemic clinical and experimental research began demonstrating cell- and humoral-mediated immune suppression were linked to adverse psychological processes (Kiecolt-Glaser \& Glaser, 1981). As the effects of perceived psychological stress, depressive symptomology, and traumatic life events on the immune system were of increasing interest at the time, these factors were quickly adopted to studies on HIV disease progression (Antoni et al., 1990). The earliest longitudinal studies nearly exclusively targeted men who have sex with men (MSM) and provided little evidence for the effect of psychosocial functioning (e.g., psychological distress, social support and coping) on change in CD4+ lymphocyte counts out to 12 months (Kessler \& Foster, 1991; Patterson et al., 1996; Perry et al., 1992; Rabkin et al., 1991; Vassend et al., 1997), but rather severity of physical symptoms. Comparatively larger effect sizes were, however, evinced over 3-4 year intervals for low social support, concealment of HIV status and AIDS-related bereavement suggesting factors related to the availability of social attachment impact cell-mediated immunity in MSM (Cole et al., 1996; Kemeny \& Dean, 1995; Theorell et al., 1995). Stronger evidence has been garnered in support of psychological distress (including traumatic life events and depression), lack of hardiness and low acceptance/high denial coping on accelerated progression to AIDS in MSM from 6 months out to 9 years (Cole et al., 1996; Ironson et al., 1994; Mulder et al., 1995a, 1995b; Page-Shafer et al., 1996; Rabkin et al., 1991; Thornton et al., 2000).

During this period advancements were also made in understanding the role of stress hormones such as cortisol in the elevated symptom burden and disease progression with particular focus on the glucocorticoid-mediated shift from Th1-like to Th2-like $\mathrm{T}$ cell activation (Clerici et al., 1997; Kumar et al., 1993). Commensurate with these efforts and the focus on disease progression and CD4+ $\mathrm{T}$-cell decline was an emphasis on cognitive and behavioral stress management (CBSM) interventions. These interventions were designed to equip $\mathrm{HIV}+$ individuals with the physiological (e.g., deep breathing and muscle relaxation) and cognitive (e.g., restructuring) strategies to manage the chronic physical and psychological burden of HIV by mitigating cortisol-related immune suppression. The overall efficacy for these interventions on immune outcomes, based upon intent-to-treat analyses, is provocative with effects evident for 10-week CBSM on buffering CD4+ T-cell decline (Antoni et al., 1991; Goodkin et al., 1998) compared to equivocal findings for 6-week (Cleary et al., 1995), 8-week (Coates et al., 1989), and 15-week (Mulder et al., 1995a, 1995b) interventions. At the time, these studies suggest efficacy of CBSM on CD4+ T-cell counts were in part dependent upon time of exposure and parallel decrements in levels of psychological distress. Nevertheless, these studies were able to provide support for 10-week CBSM or relaxation interventions on the reduction of anxious and depressive symptomology in persons living with HIV/AIDS (for review see Carrico and Antoni, 2008).

\section{Psychosocial predictors of viral load suppression in the ERA of HAART}

With the widespread availability of HAART during the late 1990s came a dramatic decline in mortality attributed to AIDS complications throughout North America and Europe (Hogg et al., 1997; Mocroft et al., 2003). Prior to this era medical records provided the main source of information regarding disease progression. However, advances in the development of HIV-1 viral load assays and reductions in cost for reverse transcription-polymerase chain reaction (PCR)-based testing made HIV surveillance accessible to basic researchers, particularly those within resource-limited settings (Fiscus et al., 2006; Greengrass et al., 2005; Rouet et al., 2005). With decreasing rates of AIDS mortality came increased attention to biobehavioral mediators of the psychosocial risk for disease progression. Specifically, experimental and prospective evidence have been levied in support of bi-directional effects of SNS and hypothalamic pituitary adrenal (HPA) neuromodulators with clinical markers of HIV disease progression (for review see Cole, 2008). For example, a prospective study on data collected during this period revealed elevated norepinephrine (NE), urinary cortisol (CORT), depression and avoidant coping independently predicted decline in CD4+ count and/or increases in viral load (Ironson et al., 2015). The second decade of HIV research saw a continuation in the study of psychosocial factors implicated in disease progression; albeit with greater representation of women and ethnic minorities. This work revealed greater risk for depression on AIDS-related mortality in women versus men controlling for HAART (Anastos et al., 2005; Antelman et al., 2007; Bouhnik et al., 2005; Cook et al., 2004; Ickovics et al., 2001; Leserman et al., 2007; Villes et al., 2007). Importantly, depressive symptomology (reviewed in (Gonzalez et al., 2011) and antidepressant treatment (Horberg et al., 2008; Kumar \& Encinosa, 2009; 
Yun et al., 2005) were found to predict poorer HAART adherence in men and women suggesting strong relationships between psychosocial and behavioral risk factors for HIV-disease progression.

Antiretroviral medications also changed the psychosocial landscape in HIV treatment wherein positive immune and health outcomes were now attainable, thus reducing pre-occupation with thoughts of death (Taylor et al., 2000). As a result of this shift in perspective from terminal illness to chronic disease the field of positive psychology began to see expansion in research examining the immune consequence of positive psychosocial factors. Although longitudinal studies citing effects for positive psychosocial outlook, including future-oriented plans (Blomkvist et al., 1994; Mulder et al., 1995a, 1995b) and hardiness (Solano et al., 1993) in AIDS-related mortality among men were noted in the pre-HAART era, the field has since experienced considerable expansion in this line of research. In particular, positive cognitive coping strategies such as finding meaning (Bower et al., 1998; Ickovics et al., 2006) and active/problem-focused/acceptance coping (Thornton et al., 2000; Vassend \& Eskild, 1998) were linked to slower disease progression in men after adjusting for immunologic and treatment-related factors. Work from this decade also provided evidence for the effects of various forms of social support on increased survival, CD4+ count, and viral suppression controlling for HAART treatment (Ashton et al., 2005; Burgoyne, 2005; Young et al., 2004). Similar patterns were observed amongst what were considered novel psychosocial constructs. For example, higher levels of spirituality were linked to reduction of CD4+ cell decline and viral suppression in both men and women after controlling for HAART (Fitzpatrick et al., 2007; Ironson et al., 2006). With regard to stress management interventions during this period, several were found efficacious in reducing mood disturbance and improving quality of life, yet remained generally inconclusive with regards to viral suppression, buffering of CD4+ T-cell decline, and reduction in HPA-axis activity (for reviews see: Brown \& Vanable, 2008; Carrico \& Antoni, 2008; Scott-Sheldon et al., 2008).

\section{Syndemic and psychosocial factors related to immune senescence and CVD in HIV}

As we enter the 3rd decade of anti-retroviral therapy a "graying" of HIV has become evident with close to $50 \%$ of the seropositive U.S. population estimated over the age of 50 , a number that was close to $15 \%$ in the early 2000 's (Justice, 2010; Part, 2012). This follows with global trends as in 2013, an estimated 4.2 million (4.0-4.5 million) people aged 50 years and older were living with HIV across the globe, a number which has more than doubled since 1995 (Mahy et al., 2014). With advancing age comes the pursuit of medical care for typical age-related complications ranging from menopause and rheumatoid arthritis to cognitive decline. Research in older adults with HIV suggest psychosocial factors such as stigma and depression might delay the seeking-out of health care, hamper appointment attendance (Emlet, 2006; Grov et al., 2010; Havlik et al., 2011; Pence et al., 2018; RodriguezPenney et al., 2013; Rubtsova et al., 2017; Sankar et al., 2011; Shippy \& Karpiak, 2005). While negative psychosocial interactions for aging are expected, a metaanalysis highlighting a dozen studies of older adults with HIV revealed decreased short- and long-term risk for nonadherence to HAART, suggesting that some aspects of HIV self-care may be enhanced with older age (Ghidei et al., 2013).

Perhaps the greatest shift in HIV surveillance in recent years is the emergence of cardiovascular disease (CVD) as the leading cause of mortality in people living with HIV/ AIDS (PLWHA) (Islam et al., 2012; Mottillo et al., 2010); and that this may be partially attributable to chronic exposure to HAART (Bavinger et al., 2013). In particular, $\mathrm{HIV}+$ individuals are shown to have a $50 \%$ increased risk for sudden cardiac death due to acute myocardial infarction beyond that explained by recognized risk factors (Freiberg et al., 2013). Concomitantly, there has been growing interest in psychosocial risk factors for CVD progression in PLWHA. For example, trait alexithymia has been linked to greater intima-media thickness, presence of carotid plaques and vascular events in HIV+ individuals and SNS/HPA function, indexed by the ratio of NE to CORT (McIntosh et al., 2014; Parruti et al., 2013; Vadini et al., 2010). Levels of depression also predict increase in risk for CHD over 9.5 years in HIV+ women (Schwartz et al., 2012). Another study found that 12-month change in 24-h urinary CORT output mediated the effect of anger on diastolic but not systolic blood pressure in HIV+ adults (McIntosh et al., 2017). In one of the largest studies of date conducted on over 25,000 HIV+ veterans, diagnosis of major depressive disorder predicted increased risk for heart failure after adjusting for non-HIV related confounders (White et al., 2015). It has also become evident that elevated rates of depression in PLWHA may contribute to cardiometabolic disease through an erosion in health behaviors such as physical activity (Quiles et al., 2017). Thus, the interactive effect of psychosocial factors and health behaviors may become a fruitful area of research to address the burden of disease comorbidity in older adults living with HIV/AIDS.

It is important to note that interventions for HIV-related disease outcomes have also evolved over recent years with respect to mind-body practice and mobile technology. For instance, structured 6-8-week mindfulness based stress reduction (MBSR) interventions aimed at increasing levels 
of dispositional mindfulness predicted increases in CD4+ count (Creswell et al., 2009; Gonzalez-Garcia et al., 2014; SeyedAlinaghi et al., 2012), elevations in natural killer cell activity (Robinson et al., 2003) and decreases in psychological distress (Duncan et al., 2012; Gayner et al., 2012; Parhoon et al., 2017; SeyedAlinaghi et al., 2012). However, as with CBSM interventions in prior decades MBSR is limited by factors relating to implementation and scalability. Emergent studies are, however, showing potential efficacy for telephone-delivered mindfulness training in PLWH (Rosen et al., 2017). While these telephone, text, and computer-based interventions for behavioral stress management and medication adherence have shown promise (Jongbloed et al., 2015; Kempf et al., 2015; Pellowski \& Kalichman, 2012), there is still ground to cover in terms of understanding the neuro-immune mechanisms that lead to CVD comorbidity in PLWHA and the psychosocial factors that mitigate these processes. While psychosocial and behavioral interventions may not substitute for traditional treatment of the virus, research into effects on different biomarkers is needed as these interventions may play a pivotal role in reducing the burden of chronic HIV-CVD comorbidity with advancing age.

\section{Psychosocial risk factors and cancer progression and clinical health outcomes}

Cancer is actually a group of many different diseases and subtypes characterized by the abnormal and uncontrolled growth of cells, and is among the most common causes of death and morbidity worldwide. In 2018, there were roughly 18 million cancer cases worldwide, with 9.5 million in men and 8.5 million in women. Worldwide it has been estimated that there will be 23.6 million new cases of cancer each year by 2030 (Bray et al., 2018). Within the U.S. the annual incidence of cancer is estimated to be over 1.7 million with over 600,000 deaths in 2018. However, from 2006 to 2015 cancer death rates in the U.S. decreased by $1.8 \%$ in men and $1.4 \%$ in women, owing to advances in screening and early detection, as well as emerging models of precision cancer care propelled by a better understanding of the role of the human genome in the development and course of different cancers. By 2016, there were an estimated 15.5 million cancer survivors in the U.S. with the number of survivors expected to rise to 20.3 million by 2026 (Noone et al., 2018). This clearly establishes the many types of cancer as chronic diseases affecting a large population of patients and families living with its burden. Importantly, multiple biological and behavioral factors have been shown to contribute to differences in disease recurrence and mortality, and many of these have been the target of behavioral medicine research over the past 4 decades (Antoni et al., 2006a, 2006b, 2006c; Lutgendorf et al., 2010).

Multiple models linking psychosocial factors to negative health outcomes in cancer patients have been proposed and tested to date. Psychosocial adversity factors during and after a cancer diagnosis relate to poorer quality of life and health outcomes by way of biobehavioral processes (Andersen et al., 1994; Antoni et al., 2006a, 2006b, 2006c). Conversely, psychosocial interventions have decreased psychosocial adversity, modulated biobehavioral processes and improved health outcomes in diagnosed cancer patients (for reviews see Antoni, 2013; Lutgendorf \& Andersen, 2015).

\section{Stress of cancer and its treatment: psychological adaptation and physiological responses}

Receiving a cancer diagnosis and undergoing treatment generates multiple stressors and intense demands on a patient's psychological adaptation (Antoni, 2013). This set of experiences occurs initially over a period of curative (surgical) and adjuvant treatments (primary treatment), followed by an extended monitoring throughout diseasefree survivorship, and possibly a later diagnosis of recurrence and subsequent rounds of treatment. The most widely cited concerns of patients diagnosed with cancer involve fears of recurrence, physical effects of adjuvant therapy, not seeing children grow-up, premature death, and loss of social ties and activities (Stanton, 2006; Spencer et al., 1999). Difficulties in adapting to the challenges of primary treatment may result in increased anxiety and intrusive thoughts, depressive symptoms and negative affect, and social disruption, among others (Ganz et al., 2002; Stanton, 2006). Poorer psychological adaptation after diagnosis and during treatment predicts diminished quality of life (QoL) many years later (Carver et al., 2005; Steginga et al., 2009; Wenzel et al., 2005).

A variety of psychosocial factors play a major role in shaping patients' adaptation. Cognitive factors such as maintaining optimistic rational stressor appraisals and using specific coping strategies (e.g., restructuring thoughts, active coping) may enhance adaptation and QoL during treatment and years later (Brothers \& Andersen, 2009; Carver et al., 2005). Behavioral factors (e.g., using relaxation, practicing meditation and remaining physically active during treatment) are associated with less distress and better adaptation during and after cancer treatment (Fisher et al., 2017, in press; Andersen et al., 2007a, 2007b; McGregor \& Antoni, 2009). Social/interpersonal factors such as social support and interpersonal skills are associated with better psychological adaptation (Talley et al., 2010; Figueiredo et al., 2004; Friedman et al., 2005; Wimberly et al., 2005). Thus, cancer patients may psy- 
chologically adapt better or worse to the stressors of cancer diagnosis and treatment as a function of the cognitive, behavioral and social skills and resources they possess to navigate them. A wide variety of other psychosocial factors may also be at play (e.g., health literacy, health and illness beliefs, cultural factors, socioeconomic factors, access to healthcare).

\section{Psychosocial risk factors and clinical health outcomes in cancer}

Many psychosocial risk factors signaling poor psychological adaptation to cancer (e.g., chronic stress, depression, social isolation) have been associated with poorer clinical outcomes in breast (Antoni et al., 2017a, 2017b; GieseDavis et al., 2011; Pinquart \& Duberstein, 2010), skin (Dhabhar et al., 2012), ovarian (Lutgendorf et al., 2012; Schrepf et al., 2015), renal (Cohen et al., 2012), hepatocellular (Steel et al., 2007), colorectal (Ben-Eliyahu 2015) and hematologic cancers (El-Jawarhi et al., 2017; Knight et al., 2015). While the bulk of the literature tying psychosocial factors to poorer cancer outcomes focuses on stress factors (Chida et al., 2008) and depression (Pinquart \& Duberstein, 2010), there is also evidence that positive psychosocial characteristics such as social support and social well-being are related to better longer-term health outcomes (Kroenke et al., 2017; Nausheen et al., 2009; Pinquart \& Duberstein, 2010; Weihs et al., 2008).

\section{Psychosocial risk factors, and biobehavioral processes in cancer}

Physiological processes (e.g., SNS and HPA signaling) may change in parallel with changes in psychological adaptation occurring as the stress of cancer is experienced. Importantly, poorer adaptation following stress (e.g., distress states, negative affect, social adversity) may alter the behavior of immune and tumor cells via neuroendocrine signaling in ways that can enhance tumor growth and increase the odds of metastasis, thereby affecting long-term quality of life and health outcomes (Antoni, 2013; Lutgendorf et al., 2010). Specifically, cortisol and norepinephrine have been shown to modulate immune cells (e.g., increasing inflammatory signaling), which may act as stromal cells influencing processes in circulating tumor cells and specifically in the tumor microenvironment (e.g., increased angiogenesis to enhance access to blood supply and energy, and propagating endothelial-to-mesenchymal transition [EMT] tumor cells as part of a wound-healing response) (Cole et al., 2015). These changes can facilitate cancer cell growth, invasion and survival in the blood and lymph circulation, and ultimately metastasis to distant sites, which is often fatal (Antoni et al., 2006a, 2006b, 2006c; Cole et al., 2015; Lutgendorf et al., 2010). The past decade has witnessed evidence that several adversity factors (distress, negative affect, depressive symptoms, social disruption) are associated with many of these biological processes in many types of cancer, which could begin to explain links between these psychosocial factors and clinical outcomes. Here we provide a sample of this evidence, though more extensive reviews on the topic are available (Antoni, 2013; Lutgendorf \& Andersen, 2015; Lutgendorf et al., 2010).

\section{Breast cancer}

Multiple indicators of adversity (cancer-specific distress/ intrusive thoughts, negative affect, depressive symptoms, social adversity) relate to inflammation (serum cytokines, and leukocyte gene expression) in breast cancer patients (Antoni et al., 2012; Bouchard et al., 2016; Hughes et al., 2014). For instance, greater depressive symptoms and negative affect related to greater serum TNF- $\alpha$, IL- $1 \beta$ and IL-6 in breast cancer patients in the weeks after surgery (Bouchard et al., 2016). Greater negative affect and less positive affect related to greater leukocyte gene expression for pro-inflammatory cytokines (TNFA, IL6), inflammatory chemokines and related receptors, prostaglandin-synthesis enzyme COX2 (PTGS2), and tissue remodeling and epithelial-mesenchymal transition-related genes (e.g., MMP-9) (Antoni et al., 2012). Bioinformatics analyses confirmed that these genes upregulated with greater negative affect were disproportionately associated with pro-inflammatory and wound healing activities, implicating nuclear factor-kappa B (NFkB) and STAT family transcriptional pathways. In that cohort, greater post-surgical depressive symptoms predicted shorter 11-year overall survival (Antoni et al., 2017b). Thus, greater psychosocial adversity is related to immune cell behavior in ways that can influence inflammatory signaling and possibly clinical outcomes in women under treatment for breast cancer.

\section{Renal cancer}

Remarkably similar associations have been identified in other cancers. For instance, greater depressive symptoms were associated with greater leukocyte pro-inflammatory (cytokine, chemokine, COX2/prostaglandin E [PGE]), and pro-metastatic gene expression in patients with metastatic renal cell carcinoma, consistent with increased activity of NFKB and STAT1 transcription factors and factors involved in myeloid cell activation and differentiation (Cohen et al., 2012). Analyses of the tumor microenvironment showed that patients with greater depressive symptoms had greater numbers of CD68+ tumor associated 
macrophages and greater pro-inflammatory $(C O X 2 / P G E)$ and pro-metastatic $(M M P 2, M M P 9)$ gene expression in tumor tissue (Cohen et al., 2012). Greater depressive symptoms also predicted shorter survival time in this cohort. Thus in a second major cancer type, greater adversity was associated with greater concurrent inflammatory signaling and poorer clinical disease outcomes over time.

\section{Ovarian cancer}

In ovarian cancer, adversity indicators (depression, low social support, social isolation) have been related to greater inflammatory gene expression in ovarian tissue, (Lutgendorf et al., 2008); greater levels of tumor promoters [vascular endothelial growth factor (VEGF) and IL-6 (Lutgendorf et al., 2002, 2008); greater tumor-infiltrating macrophage expression for these tumor promoters (Lutgendorf et al., 2008); and shorter survival (Lutgendorf et al., 2012). In a recent study providing in vivo analysis of dynamic changes in circulating tumor cells (exosomes) prior to surgery, advanced ovarian cancer patients with low social support (vs. high social support) showed a gene expression pattern favoring up-regulated EMT (Lutgendorf et al., 2017). Secondary analyses implicated upregulation of genes associated with heightened SNS activity (cyclic adenosine monophosphate response element [CREB]) and $\mathrm{NF \kappa B}$ family transcription factors (Lutgendorf et al., 2017). This work supports the hypothesis that greater adversity in the peri-surgical period for ovarian cancer, as in the case of breast cancer, and in renal cancer, is associated with greater inflammatory signaling, molecular processes favoring metastasis, and poorer clinical outcomes.

These findings are not limited to the cancers reviewed here. For example, lower socioeconomic status (SES) has been related to greater leukocyte pro-inflammatory and pro-metastatic and lower anti-viral gene expression, and to predict increased relapse risk and decreased leukemia-free survival in recipients of hematopoietic stem cell transplant for acute myelogenous leukemia (Knight et al., 2015). These studies support the need for interventions to reduce adversity early in the cancer experience (i.e., during primary treatment) to modulate immune and inflammatory activities in order to improve the trajectory of disease.

\section{Effects of psychosocial interventions in cancer patients}

Despite an impressive number of psychological interventions tested in randomized trials with cancer patients to date (Antoni, 2013; McGregor \& Antoni, 2009; Newell et al., 2002) very few studies have been shown to (a) modulate psychological adaptation (decrease distress and adversity states) in cancer patients in parallel with (b) changes in indicators of stress physiology, (c) alterations in immune activity, and (d) long-term effects on quality of life and disease course (recurrence, mortality). Such studies require investigators to recruit cancer patients into an intervention trial at a critical juncture in the cancer continuum (e.g., time of primary treatment or at the point of disease recurrence); induce improvements in psychological (e.g., mood) and neuroendocrine (SNS and HPA) activity and immune cells (inflammation, cellular immunity) and possibly circulating tumor cells; and follow cohorts for several years for clinical outcomes.

It has been 30 years since the publication of a landmark study reported that women with metastatic breast cancer who received a 12-month group-based supportive expression therapy (SET) intervention lived 1.5 years longer than patients assigned to standard cancer care (Spiegel et al., 1989). Among three clinical trials (Goodwin et al., 2001; Kissane et al., 2007; Spiegel et al., 2007) published over the past 17 years, evaluating the effects of 12-month SET interventions on disease recurrence and survival in women with metastatic disease, two (Goodwin et al., 2001; Kissane et al., 2007) showed no survival advantage for women assigned to SET, while the third (Spiegel et al., 2007) did not show an overall survival effect for SET, although secondary analyses showed that women with estrogen receptor (ER) negative tumors assigned to SET had greater survival. There is also some evidence that palliative care interventions to improve symptom management are associated with greater survival in lung cancer patients (Temel et al., 2010). Although these interventions have shown to produce significant improvements in psychological and health outcomes, any biobehavioral processes underlying their effects on clinical disease outcomes remain unknown.

One meta-analysis of 15 randomized trials meeting stringent Cochrane criteria for methodological quality involving nearly 3000 cancer patients indicated that while psychosocial interventions did not provide an overall survival benefit, those interventions delivered early in disease (in 6 trials with 1448 patients with non-metastatic disease) were associated with a reduced risk of cancer mortality $(\mathrm{Oh}$ et al., 2016). This pattern of results and the lack of consistent effects for the SET studies noted above may be due to the fact that testing the effects of psychosocial interventions on disease course in patients with metastatic disease may be complicated by variability in time since diagnosis, multi-organ involvement, and heterogeneous treatment regimens, among others. But is there any evidence that psychosocial interventions delivered early in the treatment of non-metastatic cancer patients (i.e., in the post-surgical period) are associated with stress/distress 
reduction, changes in biobehavioral parameters, and better survival and recurrence outcomes?

Because modifiable cognitive, behavioral, and social factors can facilitate adaptation during active treatment, clinical trials have tested the effects of various cognitive behavioral therapy (CBT)-based psychosocial interventions designed to improve these factors at various points along the cancer continuum, which appear to improve psychological adaptation and clinical health outcomes, and modulate biobehavioral processes known to be related to cancer disease progression (Antoni, 2013; Lutgendorf \& Andersen, 2015). Two studies completing survival analyses in the last 10 years have, in fact, shown in post-surgical nonmetastatic breast cancer patients that group CBT-based stress management interventions improve psychological adaptation (reduced distress, negative affect, depressive symptoms, social adversity) (Andersen et al., 2004; Antoni et al., 2006a, 2006b), modulate cellular immune and/or inflammatory processes in salubrious ways (Andersen et al., 2004; Antoni et al., 2009, 2012, 2016), and show better disease course (greater disease-free intervention and survival time over 11-year median follow-up) (Andersen et al., 2008; Stagl et al., 2015). Secondary analyses revealed that immunologic changes occurring during the first year of primary treatment (decreased leukocyte inflammatory and increased anti-viral gene expression, Antoni et al., 2016) and later in cancer survivorship (lower total white blood cell and neutrophil counts, Thornton et al., 2008/2009; Andersen et al., 2010) predict better long-term clinical outcomes (e.g., longer time to recurrence) in these cohorts.

Neuroendocrine changes observed in one of these trials may provide insights into the physiological processes that may underlie intervention effects (Phillips et al., 2008). Women assigned to the 10-week CBSM intervention revealed decreases in afternoon serum cortisol levels over a 1-year follow-up (Phillips et al., 2008) that paralleled decreases in negative affect, cancer-specific intrusive thoughts, and social disruption (Antoni et al., 2006a, 2006b). Transcriptional analyses revealed that these women also showed decreased leukocyte pro-inflammatory and pro-metastatic gene expression in tandem with increased glucocorticoid (GC) receptor gene expression, implicating reduced $\mathrm{GC}$ resistance as a possible mediator of intervention effects on decreased inflammatory signaling (Antoni et al., 2012). The finding that increased leukocyte GC sensitivity occurred in breast cancer patients demonstrating decreasing circulating cortisol levels suggests that stress management interventions capable of decreasing circulating GC ligands may over time improve leukocyte sensitivity to anti-inflammatory signals. This notion is supported by evidence that distress, depression and other states of adversity may contribute to inflammatory signal- ing by way of GC resistance (Miller et al., 2002) and provides some of the first evidence that a CBT-based intervention may reverse both HPA axis dysregulation and inflammatory signaling in cancer patients.

Thus, CBT-based stress management interventions may improve long-term health outcomes in non-metastatic breast cancer patients by modulating immune cell behaviors (e.g., inflammation, anti-viral immune signaling and function), which in turn may communicate with cancer cells in order to promote their survival, progression and metastasis. Since neuroendocrine and immunological/inflammatory changes are known to relate to stress processes on the one hand and breast cancer disease progression on the other (Antoni et al., 2006a, 2006b, 2006c) it follows that stress reduction may reverse neuroendocrine dysregulation (e.g., by decreasing SNS-and HPA-mediated production of neuroendocrines, and decreasing GC receptor resistance in circulating immune cells, Miller et al., 2002). Immunologic effects of these changes may lead to a restoration of cellular and antiviral immunity (increased lymphocyte proliferative responses, Type I and II interferon signaling, Th1 cytokine production), and a decrease in inflammatory expression patterns (decreased leukocyte pro-inflammatory and pro-metastatic signaling, and circulating cytokines) (Cole et al., 2015). Together these immunologic changes could contribute to improved longterm (e.g., time to recurrence) health effects in breast cancer patients. For instance, stress-induced SNS activation, which can accompany many adverse conditions, may promote a myeloid-mediated "metastatic switch" within a growing primary tumor to increase the odds of distant metastases (Sloan et al., 2010).

Despite being conducted by separate laboratories the two CBT-based stress management trials (Andersen et al., 2008; Stagl et al., 2015) were comparable in terms of sampling approach (recruiting approximately equal numbers post-surgical patients), intervention format and content, and follow-up intervals (psychological and immune measures over 12 months; disease outcomes over 8-15 years (median $=11$ years). In each trial, distress and/or cortisol decreases were paralleled by either increased frequency of relaxation practice (Andersen et al., 2007b) or increased confidence in using relaxation to manage stress (Antoni et al., 2006a, 2006b, 2006c; Phillips et al., 2011). This provides some insight into one of the possible mediators of these interventions (i.e., anxiety-tension reduction) that may explain their effects on biobehavioral processes and health outcomes. Although the disease stage range of the samples did differ, when stage was matched between the two trials (i.e., using Stage II-III cases only) very similar results for each trial emerged for intervention effects on survival and recurrence. Differences in the trials did include a longer period of continuous intervention 
(12 months for Andersen et al. vs. 10 weeks of Stagl et al.), and an additional focus on heath behavior change in Andersen et al. It may thus be possible to achieve longterm health benefits in the briefer program with a sole focus on stress management skills training.

Exciting new developments in cancer treatments include various forms of neoadjuvant (pre-surgical) chemotherapy, radiotherapy and immunotherapy; less toxic adjuvant chemotherapy regimens, minimal dose radiation therapies, and immunotherapies using chimeric antigen receptor (CAR) T-cells and checkpoint inhibitor therapies; and the application of these and other treatment approaches on the basis of the genetic characteristics of tumor cells, often referred to as "precision" approaches. Estimated national expenditures for cancer care in the US in 2017 were nearly $\$ 150$ billion. The National Cancer Institute has noted that in future years, costs are likely to increase as the population ages, cancer prevalence increases, and some of the new, and often more expensive, treatments noted above are adopted as standards of care. Many of these cutting edge approaches remain quite expensive and out of reach of the majority of patients, who must rely instead on standardized and higher burden surgical, chemotherapy and radiation therapies, which will create or exacerbate cancer health disparities. The work presented in this review provides preliminary support for the value of using psychosocial interventions as adjunctive strategies to modulate psychological and physiological adaptation early in treatment, monitoring changes in biobehavioral processes reflecting cellular immune functioning, inflammation and other tumor-promoting processes during cancer survivorship, and following cohorts systematically for effects on clinical outcomes. Future work should use community-based approaches, culturally adapted interventions, and advances in remote technologies to increase the reach of these research findings.

\section{Summary and conclusions}

During the past 40 years since the Yale conference on Behavioral Medicine and the founding of the Journal of Behavioral Medicine considerable progress has been made in understanding the role of psychosocial risk and management of a number of chronic physical diseases. The effects of prolonged distress responses in the pathogenesis of some cancers and cardiovascular diseases have become well-established and modifiable cognitive, behavioral and social factors have been shown to produce some favorable outcomes in the management of such diseases as breast cancer, CHD and HIV. It should be noted that psychosocial interventions such as CBT-based stress management have been successful in improving long-term clinical disease endpoints including survival. Emerging work is identifying the active ingredients of these interventions in order to refine them and determine the optimal timing and duration of their delivery, while incorporating technological advances to increase their reach. It is important to note that the psychosocial-behavioral interventions have not been a substitute for traditional medical care including surgery and medications, but instead have become an important part of the armamentarium of modern health care.

Acknowledgements Neil Schneiderman thanks Stephen M. Weiss as a long-time friend, colleague and scientific collaborator. He receives support as the James L. Knight Chair in Health Psychology and from NIH (HHSN2682013000041). Roger C. McIntosh receives support from NIH K01-HL139722 and his membership in the behavioral/social/community outreach program in the University of Miami Center for AIDS Research (CFAR). Michael H. Antoni receives support from NIH (CA064710, CA131451, HHSN261200800015), Florida Department of Health (6BC06), Florida Breast Cancer Foundation, and the University of Miami School of Medicine Sylvester Comprehensive Cancer Center.

\section{Compliance with ethical standards}

Conflicts of interest Neil Schneiderman and Roger C. McIntosh declare they have no conflicts of interest. Michael H. Antoni receives royalties from a book on stress management in breast cancer patients.

Human and animal rights and Informed consent All procedures performed in studies involving human participants carried out by the authors were in accordance with the ethical standards of the institutional and/or national research committee and with the 1964 Helsinki declaration and its later amendments or comparable ethical standards. All applicable international, national, and/or institutional guidelines for the care and use of animals were followed by the authors for studies they were involved with using animals.

\section{References}

Adams, D. B., Bacelli, G., Mancia, G., \& Zanchetti, A. (1968). Cardiovascular changes during naturally elicited fighting behavior in the cat. American Journal of Physiology, 216, 1226-1235.

American Heart Association (AMA). (2010). Heart disease and stroke statistics - 2010 update [Glance version]. Retrieved from http://www.americanheart.org/downloadable/heart_ 1265665152970DS-324\%20HeartStrokeUpdate_2010.pdf

Anastos, K., Schneider, M. F., Gange, S. J., Minkoff, H., Greenblatt, R. M., Feldman, J., et al. (2005). The association of race, sociodemographic, and behavioral characteristics with response to highly active antiretroviral therapy in women. JAIDS Journal of Acquired Immune Deficiency Syndromes, 39, 537-544.

Andersen, B. L., Farrar, W. B., Golden-Kreutz, D., Emery, C. F., Glaser, R., Crespin, T., et al. (2007a). Distress reduction from a psychological intervention contributes to improved health for cancer patients. Brain, Behavior, and Immunity, 21, 953-961.

Andersen, B., Farrar, W. B., Golden-Kreutz, D. M., Glaser, R., Emery, C. F., Crespin, T. R., et al. (2004). Psychological, behavioral, and immune changes after a psychological intervention: A clinical trial. Journal of Clinical Oncology, 22, $3570-3580$. 
Andersen, B. L., Kiecolt-Glaser, J. K., \& Glaser, R. (1994). A biobehavioral model of cancer stress and disease course. American Psychologist, 49, 389-404.

Andersen, B., Shelby, R., \& Golden-Kruetz, D. (2007b). RCT of a psychological intervention for persons with cancer. I. Mechanisms of change. Journal of Consulting and Clinical Psychology, 75, 927-938.

Andersen, B. L., Thornton, L., Shapiro, C., Farrar, W., Mundy, B., Yang, H., et al. (2010). Biobehavioral, immune and health benefits following recurrence for psychological intervention participants. Clinical Cancer Research, 16, 3270-3278.

Andersen, B. L., Yang, H. C., Farrar, W. B., Golden-Kreutz, D. M., Emery, C. F., Thornton, L. M., et al. (2008). Psychologic intervention improves survival for breast cancer patients: A randomized clinical trial. Cancer, 113, 3450-3458.

Antelman, G., Kaaya, S., Wei, R., Mbwambo, J., Msamanga, G. I., Fawzi, W. W., et al. (2007). Depressive symptoms increase risk of HIV disease progression and mortality among women in Tanzania. JAIDS Journal of Acquired Immune Deficiency Syndromes, 44, 470-477.

Antoni, M. H. (2013). Psychosocial intervention effects on adaptation, disease course and biobehavioral processes in cancer. Brain, Behavior, and Immunity, 30, S88-S89.

Antoni, M. H., Baggett, L., Ironson, G., LaPerriere, A., August, S., Klimas, N., et al. (1991). Cognitive-behavioral stress management intervention buffers distress responses and immunologic changes following notification of HIV-1 seropositivity. Journal of Consulting and Clinical Psychology, 59, 906.

Antoni, M. H., Bouchard, L. C., Jacobs, J. M., Lechner, S. C., Jutagir, D. R., Gudenkauf, L. M., et al. (2016). Stress management, leukocyte transcriptional changes and breast cancer recurrence in a randomized trial: An exploratory analysis. Psychoneuroendocrinology, 74, 269-277.

Antoni, M., Frasca, D., Diaz, A., Fisher, H., Taub, C., Czaja, S., et al. (2017). Video-conferenced stress management and relaxation training for older women with breast cancer: VSMART. In Presented at the Sylvester Comprehensive Cancer Center Retreat.

Antoni, M. H., Jacobs, J. M., Bouchard, L. C., Lechner, S. C., Jutagir, D. R., Gudenkauf, L. M., et al. (2017b). Post-surgical depressive symptoms and long-term survival in non-metastatic breast cancer patients at 11-year follow-up. General Hospital Psychiatry, 44, $16-21$.

Antoni, M. H., Lechner, S., Diaz, A., Vargas, S., Holley, H., Phillips, K., et al. (2009). Cognitive behavioral stress management effects on psychosocial and physiological adaptation in women undergoing treatment for breast cancer. Brain, Behavior, and Immunity, 23, 159-166.

Antoni, M. H., Lechner, S. C., Kazi, A., Wimberly, S., Gluck, S., \& Carver, C. S. (2006a). How stress management improves quality of life after breast cancer treatment. Journal of Consulting and Clinical Psychology, 74, 1143-1152.

Antoni, M. H., Lutgendorf, S., Blomberg, B., Carver, C. S., Lechner, S., Diaz, A., et al. (2012). Cognitive-behavioral stress management reverses anxiety-related leukocyte transcriptional dynamics. Biological Psychiatry, 71, 366-372.

Antoni, M. H., Lutgendorf, S., Cole, S., Dhabhar, F., Sephton, S., McDonald, P., et al. (2006b). The influence of biobehavioral factors on tumor biology: Pathways and mechanisms. Nature Reviews Cancer, 6, 240-248.

Antoni, M. H., Schneiderman, N., Fletcher, M. A., Goldstein, D. A., Ironson, G., \& Laperriere, A. (1990). Psychoneuroimmunology and HIV-1. Journal of Consulting and Clinical Psychology, 58, 38.

Antoni, M. H., Wimberly, S. R., Lechner, S. C., Kazi, A., Sifre, T., Urcuyo, K. R., et al. (2006c). Reduction of cancer-specific thought intrusions and anxiety symptoms with a stress management intervention among women undergoing treatment for breast cancer. American Journal of Psychiatry, 163, 1791-1797.

Ashton, E., Vosvick, M., Chesney, M., Gore-Felton, C., Koopman, C., O'shea, K., et al. (2005). Social support and maladaptive coping as predictors of the change in physical health symptoms among persons living with HIV/AIDS. AIDS Patient Care \& STDs, 19, 587-598.

Bavinger, C., Bendavid, E., Niehaus, K., Olshen, R. A., Olkin, I., Sundaram, V., et al. (2013). Risk of cardiovascular disease from antiretroviral therapy for HIV: a systematic review. PLOS ONE, 8 , e59551.

Ben-Eliyahu, S. (2015). Cancer metastasis: Promotion by stress and surgery. In Opp, M. (Ed.), Primer of psychoneuroimmunology research. Psychoneuroimmunologic Research Society.

Berkman, L. F., Blumenthal, J., Burg, M., Carney, R. M., Catellier, D., Enhancing Recovery in Coronary Heart Disease Patients Investigators [ENRICHD], et al. (2003). Effects of treating depression and low perceived social support on clinical events after myocardial infarction: The Enhancing Recovery in Coronary Heart Disease Patients (ENRICHD) Randomized Trial. Journal of the American Medical Association, 289, 2106-3116.

Bernard, C. (1865/1961). An introduction to the study of experimental medicine (H. C. Greene, Trans.). New York: Collier.

Blomkvist, V., Theorell, T., Jonsson, H., Schulman, S., Berntorp, E., \& Stiegendal, L. (1994). Psychosocial self-prognosis in relation to mortality and morbidity in hemophiliacs with HIV infection. Psychotherapy and Psychosomatics, 62, 185-192.

Blumenthal, J. A., Babyak, M. A., O'Connor, C., Keteryian, S., Landzberg, J., Howlett, J., et al. (2012). Effects of exercise training on depressive symptoms in patients with chronic heart failure. The HF-ACTION randomized trial. Journal of the American Medical Association, 308, 465-474.

Bouchard, L. C., Antoni, M. H., Blomberg, B. B., Stagl, J. M., Gudenkauf, L. M., Jutagir, D. R., et al. (2016). Postsurgical depressive symptoms and proinflammatory cytokine elevations in women undergoing primary treatment for breast cancer. Psychosomatic Medicine, 78, 26-37.

Bouhnik, A.-D., Préau, M., Vincent, E., Carrieri, M. P., Gallais, H., Lepeu, G., et al. (2005). Depression and clinical progression in HIV-infected drug users treated with highly active antiretroviral therapy. Antiviral Therapy, 10, 53-61.

Bower, J. E., Kemeny, M. E., Taylor, S. E., \& Fahey, J. L. (1998). Cognitive processing, discovery of meaning, CD4 decline, and AIDS-related mortality among bereaved HIV-seropositive men. Journal of Consulting and Clinical Psychology, 66, 979.

Bray, F., Ferlay, J., Soerjomataram, I., Siegel, R. L., Torre, L. A., \& Jemal, A. (2018). Global Cancer Statistics 2018: GLOBOCAN estimates of incidence and mortality worldwide for 36 cancers in 185 countries. CA A Cancer Journal for Clinicians, 68, 394-424.

Brothers, B. M., \& Andersen, B. L. (2009). Hopelessness as a predictor of depressive symptoms for breast cancer patients coping with recurrence. Psycho-Oncology, 18, 267-275.

Brown, J. L., \& Vanable, P. A. (2008). Cognitive-behavioral stress management interventions for persons living with HIV: A review and critique of the literature. Annals of Behavioral Medicine, 35, 26-40.

Buja, L. M., Clubb, F. J., Bilheimer, D. W., \& Willerson, J. T. (1990). Pathobiology of human familial hypercholesterolaemia and a related animal model, the WHHL. European Heart Journal, 11, $41-52$.

Buja, L. M., Kita, T., Goldstein, J. L., Watanabe, Y., \& Brown, M. S. (1983). Cellular pathology of progressive atherosclerosis in the WHHL rabbit. Atherosclerosis, 3, 87-101. 
Burgoyne, R. (2005). Exploring direction of causation between social support and clinical outcome for HIV-positive adults in the context of highly active antiretroviral therapy. AIDS Care, 17, 111-124.

Cannon, W. B. (1929). Bodily changes in pain, hunger, fear and rage (2nd ed.). New York: Appleton.

Carrico, A. W., \& Antoni, M. H. (2008). The effects of psychological interventions on neuroendocrine hormone regulation and immune status in HIV-positive persons: A review of randomized controlled trials. Psychosomatic Medicine, 70, 575.

Carver, C. S., Smith, R. G., Antoni, M. H., Petronis, V. M., Weiss, S., \& Derhagopian, R. P. (2005). Optimistic personality and psychosocial well-being during treatment predict psychosocial well-being among long-term survivors of breast cancer. Health Psychology, 24, 508-516.

Chida, Y., Hamer, M., Wardle, J., \& Steptoe, A. (2008). Do stressrelated psychosocial factors contribute to cancer incidence and survival? Nature Reviews Clinical Oncology, 5, 466-475.

Clarkson, T. B., Adams, M. R., Kaplan, J. R., Shively, C. A., \& Koritnik, D. R. (1989). From menarche to menopause: Coronary artery atherosclerosis and protection in cynomolgus monkeys. American Journal of Obstetrics and Gynecology, 160, $1280-1285$.

Clarkson, T. B., Kaplan, J. R., Adams, M. R., \& Manuck, S. B. (1987). Psychosocial influences on the pathogenesis of atherosclerosis among nonhuman primates. Circulation, 76, 29-40.

Cleary, P. D., Van, N. D., Steilen, M., Stuart, A., Shipton-Levy, R., McMullen, W., et al. (1995). A randomized trial of an education and support program for HIV-infected individuals. AIDS (London, England), 9, 1271-1278.

Clerici, M., Trabattoni, D., Piconi, S., Fusi, M. L., Ruzzante, S., Clerici, C., et al. (1997). A possible role for the cortisol/ anticortisols imbalance in the progression of human immunodeficiency virus. Psychoneuroendocrinology, 22, S27-S31.

Coates, T. J., McKusick, L., Kuno, R., \& Stites, D. P. (1989). Stress reduction training changed number of sexual partners but not immune function in men with HIV. American Journal of Public Health, 79, 885-887.

Cohen, L., Cole, S. W., Sood, A. K., Prinsloo, S., Kirschbaum, C., Arevalo, J. M. G., et al. (2012). Depressive symptoms and cortisol rhythmicity predict survival in patients with renal cell carcinoma: Role of inflammatory signaling. PLoS ONE, 7, e42324.

Cole, S. W. (2008). Psychosocial influences on HIV-1 disease progression: Neural, endocrine, and virologic mechanisms. Psychosomatic Medicine, 70, 562-568.

Cole, S. W., Kemeny, M. E., Taylor, S. E., Visscher, B. R., \& Fahey, J. L. (1996). Accelerated course of human immunodeficiency virus infection in gay men who conceal their homosexual identity. Psychosomatic Medicine, 58, 219-231.

Cole, S. W., Nagaraja, A. S., Lutgendorf, S. K., Green, P. A., \& Sood, A. K. (2015). Sympathetic nervous system regulation of the tumour microenvironment. Nature Reviews Cancer, 15, $563-572$.

Cook, J. A., Grey, D., Burke, J., Cohen, M. H., Gurtman, A. C., Richardson, J. L., et al. (2004). Depressive symptoms and AIDSrelated mortality among a multisite cohort of HIV-positive women. American Journal of Public Health, 94, 1133-1140.

Creswell, J. D., Myers, H. F., Cole, S. W., \& Irwin, M. R. (2009). Mindfulness meditation training effects on CD4+ T lymphocytes in HIV-1 infected adults: A small randomized controlled trial. Brain, Behavior, and Immunity, 23, 184-188.

Dhabhar, F. S., Malarkey, W. B., Neri, E., \& McEwen, B. S. (2012). Stress-induced redistribution of immune cells-From barracks to boulevards to battlefields: A tale of three hormones. Psychoneuroendocrinology, 37, 1345-1368.

Duncan, L. G., Moskowitz, J. T., Neilands, T. B., Dilworth, S. E., Hecht, F. M., \& Johnson, M. O. (2012). Mindfulness-based stress reduction for HIV treatment side effects: A randomized, wait-list controlled trial. Journal of Pain and Symptom Management, 43, $161-171$.

El-Jawarhi, A., Chen, Y., Brazauskas, R., He, N., Lee, S., Knight, J., et al. (2017). Impact of pre-transplant depression on outcomes of allogeneic and autologous hematopoietic stem cell transplantation. Cancer, 123, 1828-1838.

Emlet, C. A. (2006). An examination of the social networks and social isolation in older and younger adults living with HIV/AIDS. Health and Social Work, 31, 299-308.

Figueiredo, M. I., Fries, E., \& Ingram, K. M. (2004). The role of disclosure patterns and unsupportive social interactions in the well-being of breast cancer patients. Psycho-Oncology, 13, 96-105.

Fiscus, S. A., Cheng, B., Crowe, S. M., Demeter, L., Jennings, C., Miller, V., et al. (2006). HIV-1 viral load assays for resourcelimited settings. PLoS Medicine, 3, e417.

Fisher, H. M., Jacobs, J. M., Taub, C. J., Lechner, S. C., Lewis, J. E., Carver, J., et al. (2017). How changes in physical activity relate to fatigue interference, mood, and quality of life during treatment for non-metastatic breast cancer. General Hospital Psychiatry, $49,37-43$.

Fitzpatrick, A. L., Standish, L. J., Berger, J., \& Kim, J. G. (2007). Survival in HIV-1-positive adults practicing psychological or spiritual activities for one year. Alternative Therapies in Health and Medicine, 13, 18.

Frasure-Smith, N., Lespérance, F., Prince, R. H., Verrier, P., Garber, R. A., Juneau, M., et al. (1997). Randomised trial of home-based psychosocial nursing intervention for patients recovering from myocardial infarction. Lancet, 350, 473-479.

Freiberg, M. S., Chang, C. C. H., Kuller, L. H., Skanderson, M., Lowy, E., Kraemer, K. L., et al. (2013). HIV infection and the risk of acute myocardial infarction. JAMA Internal Medicine, $173,614-622$.

Friedman, L. C., Kalidas, M., Elledge, R., Chang, J., Romero, C., Husain, I., et al. (2005). Optimism, social support, and psychosocial functioning among women with breast cancer. Psycho-Oncology, 15, 595-603.

Friedman, M., Thoresen, C. E., Gill, J. J., Ulmer, D., Powell, L. H., Price, V. A., et al. (1986). Alteration of type A behavior and its effect on cardiac recurrences in post myocardial infarction patients. Summary results of the recurrent coronary prevention project. American Heart Journal, 112, 653-665.

Ganz, P., Desmond, K., Leedham, B., Rowland, J., Meyerowitz, B., \& Belin, T. (2002). Quality of life in long-term. Disease-free survivors of breast cancer: a Follow-up study. Journal of the National Cancer Institute, 94, 39-49.

Gayner, B., Esplen, M. J., DeRoche, P., Wong, J., Bishop, S., Kavanagh, L., et al. (2012). A randomized controlled trial of mindfulness-based stress reduction to manage affective symptoms and improve quality of life in gay men living with HIV. Journal of Behavioral Medicine, 35, 272-285.

Ghidei, L., Simone, M. J., Salow, M. J., Zimmerman, K. M., Paquin, A. M., Skarf, L. M., et al. (2013). Aging, antiretrovirals, and adherence: A meta analysis of adherence among older HIVinfected individuals. Drugs and Aging, 30, 809-819.

Giese-Davis, J., Collie, K., Rancourt, K. M., Neri, E., Kraemer, H. C., \& Spiegel, D. (2011). Decrease in depression symptoms is associated with longer survival in patients with metastatic breast cancer: A secondary analysis. Journal of Clinical Oncology, 29, $413-420$. 
Goldberg, D. P. (1972). The assessment of psychiatric illness by questionnaire. London: Oxford University Press.

Gonzalez, J. S., Batchelder, A. W., Psaros, C., \& Safren, S. A. (2011). Depression and HIV/AIDS treatment nonadherence: A review and meta-analysis. Journal of Acquired Immune Deficiency Syndromes, 58, 181-187.

Gonzalez-Garcia, M., Ferrer, M. J., Borras, X., Munoz-Moreno, J. A., Miranda, C., Puig, J., et al. (2014). Effectiveness of mindfulnessbased cognitive therapy on the quality of life, emotional status, and CD4 cell count of patients aging with HIV infection. AIDS and Behavior, 18, 676-685.

Goodkin, K., Feaster, D. J., Asthana, D., Blaney, N. T., Kumar, M., Baldewicz, T., et al. (1998). A bereavement support group intervention is longitudinally associated with salutary effects on the CD4 cell count and number of physician visits. Clinical Diagnostic Laboratory Immunology, 5, 382-391.

Goodwin, P. J., Leszcz, M., \& Ennis, M. (2001). The effect of group psychosocial support on survival in metastatic breast cancer. The New England Journal of Medicine, 345, 1719-1726.

Gorelick, P. B., Scuteri, A., Black, S. E., DeCarli, C., Greenberg, S. M., Iadecola, C., et al. (2011). Vascular contributions to cognitive impairment and dementia: A statement for healthcare professionals from the American Heart Association/American Stroke Association. Stroke, 42, 2672-2713.

Greengrass, V. L., Turnbull, S. P., Hocking, J., Dunne, A. L., Tachedjian, G., Corrigan, G. E., et al. (2005). Evaluation of a low cost reverse transcriptase assay for plasma HIV-1 viral load monitoring. Current HIV Research, 3, 183-190.

Grov, C., Golub, S. A., Parsons, J. T., Brennan, M., \& Karpiak, S. E. (2010). Loneliness and HIV-related stigma explain depression among older HIV-positive adults. AIDS Care, 22, 630-639.

Gullikesson, M., Burell, G., Vessby, B., Lundin, L., Toss, H., \& Svärdsudd, K. (2011). Randomized controlled trial of cognitive behavioral therapy vs. standard treatment to prevent recurrent cardiovascular events in patients with coronary heart disease. Archives of Internal Medicine, 171, 134-140.

Haffner, S., Lehto, S., Rönnemaa, T., Pyörälä, K., \& Laakso, M. (1998). Mortality from coronary heart disease in subjects with type 2 diabetes and in nondiabetic subjects with and without prior myocardial infarction. New England Journal of Medicine, 339, 229-234

Havlik, R. J., Brennan, M., \& Karpiak, S. E. (2011). Comorbidities and depression in older adults with HIV. Sexual Health, 8, 551-559.

Hogg, R. S., Oshaughnessy, M. V., Gataric, N., Yip, B., Craib, K., Schechter, M. T., et al. (1997). Decline in deaths from AIDS due to new antiretrovirals. The Lancet, 349, 1294.

Horberg, M. A., Silverberg, M. J., Hurley, L. B., Towner, W. J., Klein, D. B., Bersoff-Matcha, S., et al. (2008). Effects of depression and selective serotonin reuptake inhibitor use on adherence to highly active antiretroviral therapy and on clinical outcomes in HIV-infected patients. JAIDS Journal of Acquired Immune Deficiency Syndromes, 47, 384-390.

Hughes, S., Jaremka, L. M., Alfano, C. M., Glaser, R., Povoski, S. P., Lipari, A. M., et al. (2014). Social support predicts inflammation, pain, and depressive symptoms: Longitudinal relationships among breast cancer survivors. Psychoneuroendocrinology, 42, $38-44$.

Ickovics, J. R., Hamburger, M. E., Vlahov, D., Schoenbaum, E. E., Schuman, P., Boland, R. J., et al. (2001). Mortality, CD4 cell count decline, and depressive symptoms among HIV-seropositive women: longitudinal analysis from the HIV Epidemiology Research Study. JAMA, 285, 1466-1474.

Ickovics, J. R., Milan, S., Boland, R., Schoenbaum, E., Schuman, P., Vlahov, D., et al. (2006). Psychological resources protect health: 5-year survival and immune function among HIV-infected women from four US cities. Aids, 20, 1851-1860.

Ironson, G., Friedman, A., Klimas, N., Antoni, M., Fletcher, M. A., LaPerriere, A., et al. (1994). Distress, denial, and low adherence to behavioral interventions predict faster disease progression in gay men infected with human immunodeficiency virus. International Journal of Behavioral Medicine, 1, 90-105.

Ironson, G., O'cleirigh, C., Kumar, M., Kaplan, L., Balbin, E., Kelsch, C., et al. (2015). Psychosocial and neurohormonal predictors of HIV disease progression (CD4 cells and viral load): A 4 year prospective study. AIDS and Behavior, 19, 1388-1397.

Ironson, G., Stuetzle, R., \& Fletcher, M. A. (2006). An increase in religiousness/spirituality occurs after HIV diagnosis and predicts slower disease progression over 4 years in people with HIV. Journal of General Internal Medicine, 21, S62.

Islam, F., Wu, J., Jansson, J., \& Wilson, D. (2012). Relative risk of cardiovascular disease among people living with HIV: A systematic review and meta-analysis. HIV Medicine, 13, 453-468.

Jones, D. A., \& West, R. R. (1996). Psychological rehabilitation after myocardial infarction: Multicentre randomized controlled trial. BMJ, 313, 1517-1521.

Jongbloed, K., Parmar, S., van der Kop, M., Spittal, P. M., \& Lester, R. T. (2015). Recent evidence for emerging digital technologies to support global HIV engagement in care. Current HIV/AIDS Reports, 12, 451-461.

Justice, A. C. (2010). HIV and aging: Time for a new paradigm. Current HIV/AIDS Reports, 7, 69-76.

Kaplan, J. R., Manuck, S. B., Adams, M. R., Weingand, K. W., \& Clarkson, T. B. (1987). Inhibition of coronary atherosclerosis by propranolol in behaviorally predisposed monkeys fed an atherogenic diet. Circulation, 76, 1364-1372.

Kaplan, J. R., Manuck, S. B., Clarkson, T. B., Lusso, F. M., Taub, D. M., \& Miller, E. W. (1983). Social stress and atherosclerosis in normocholesterolemic monkeys. Science, 220, 733-735.

Kemeny, M. E., \& Dean, L. (1995). Effects of AIDS-related bereavement of HIV progression among New York City gay men. AIDS Education and Prevention, 7, 36-47.

Kempf, M.-C., Huang, C.-H., Savage, R., \& Safren, S. A. (2015). Technology-delivered mental health interventions for people living with HIV/AIDS (PLWHA): A review of recent advances. Current HIV/AIDS Reports, 12, 472-480.

Kessler, R. C., \& Foster, C. (1991). Stressful life events and symptom onset in HIV infection. The American Journal of Psychiatry, 148, 733.

Kiecolt-Glaser, J. K., \& Glaser, R. (1981). Stress and immune function in humans Psychoneuroimmunology (pp. 849-867). New York: Elsevier.

Kissane, D., Grabsch, B., \& Clarke, D. (2007). Supportive-expressive group therapy for women with metastatic breast cancer: Survival and psychosocial outcomes from a randomized controlled trial. Psycho-Oncology, 16, 277-286.

Knight, J. M., Rizzo, J. D., Logan, B., Wang, T., Arevalo, J., Ma, J., et al. (2015). Low socioeconomic status, adverse gene expression profiles, and clinical outcomes in hematopoietic stem cell transplant recipients. Clinical Cancer Research, 22, 69-78.

Knowler, W. C., Barrett-Connor, E., Fowler, S. E., Hamman, R. F., Lachin, J. M., Walker, E. A., et al. (2002). Reduction in the incidence of type 2 diabetes with lifestyle intervention or metformin. New England Journal of Medicine, 346, 393-403.

Kroenke, C. H., Michael, Y. L., Poole, E. M., Kwan, M. L., Nechuta, S., Leas, E., et al. (2017). Postdiagnosis social networks and breast cancer mortality in the After Breast Cancer Pooling Project. Cancer, 123, 1228-1237. 
Kumar, V., \& Encinosa, W. (2009). Effects of antidepressant treatment on antiretroviral regimen adherence among depressed HIV-infected patients. Psychiatric Quarterly, 80, 131-141.

Kumar, M., Kumar, A. M., Morgan, R., Szapocznik, J., \& Eisdorfer, C. (1993). Abnormal pituitary-adrenocortical response in early HIV-1 infection. Journal of Acquired Immune Deficiency Syndromes, 6, 61-65.

Lacey, J. I. (1967). Somatic response patterning and stress: Some revisions of activation theory. In M. H. Appleyo \& R. Trumble (Eds.), Psychological stress (p. 14). New York: AppletonCentury-Crofts.

Lacey, J. L., \& Lacey, B. C. (1958). Verification and extension of the principle of autonomic response stereotyping. The American Journal of Psychology, 71, 50-73.

Lavie, C. J., Milani, R. V., Marks, P., \& deGruiter, H. (2001). Exercise and the heart: Risks, benefits, and recommendations for providing exercise prescriptions. Ochsner Journal, 3, 207-212.

Lazarus, R. S., \& Folkman, S. (1984). Stress, appraisal and coping. New York: Springer.

Leserman, J., Pence, B. W., Whetten, K., Mugavero, M. J., Thielman, N. M., Swartz, M. S., et al. (2007). Relation of lifetime trauma and depressive symptoms to mortality in HIV. American Journal of Psychiatry, 164, 1707-1713.

Lutgendorf, S., \& Andersen, B. (2015). Biobehavioral approaches to cancer progression and survival. American Psychologist, 70, 186-197.

Lutgendorf, S. K., De Geest, K., Bender, D., Ahmed, A., Goodheart, M. J., Dahmoush, L., et al. (2012). Social influences on clinical outcomes of patients with ovarian cancer. Journal of Clinical Oncology, 30, 2885-2890.

Lutgendorf, S. K., Johnsen, E. L., Cooper, B., Anderson, B., Sorosky, J. I., Buller, R. E., et al. (2002). Vascular endothelial growth factor and social support in patients with ovarian carcinoma. Cancer, 95, 808-815.

Lutgendorf, S. K., Lamkin, D. M., Jennings, N. B., Arevalo, J. M. G., Penedo, F., DeGeest, K., et al. (2008). Biobehavioral influences on matrix metalloproteinase expression in ovarian carcinoma. Clinical Cancer Research, 14, 6839-6846.

Lutgendorf, S. K., Sood, A., \& Antoni, M. H. (2010). Host factors and cancer progression: Biobehavioral signaling pathways and interventions. Journal of Clinical Oncology, 28, 4094-4099.

Lutgendorf, S., Thaker, P., Arevalo, J., Goodheart, M., Slavich, G., Sood, A., et al. (2017). Biobehavioral modulation of the exosome transcriptome in ovarian carcinoma. Cancer., 124, $580-586$.

Mahy, M., Autenrieth, C. S., Stanecki, K., \& Wynd, S. (2014). Increasing trends in HIV prevalence among people aged 50 years and older: evidence from estimates and survey data. AIDS (London, England), 28, S453.

Manuck, S. B., Kaplan, J. R., \& Clarkson, T. B. (1983). Behaviorally induced heart rate reactivity and atherosclerosis in cynomolgus monkeys. Psychosomatic Medicine, 45, 95-108.

Manuck, S. B., Kaplan, J. R., \& Matthews, K. A. (1986). Behavioral antecedents of coronary heart disease and atherosclerosis. Arteriosclerosis, 6, 2-14.

McCabe, P. M., Gonzales, J., Zaias, J., Szeto, A., Kumar, M., Herron, A., et al. (2002). Social environment influences the progression of atherosclerosis in the Watanabe heritable hyperlipidemic rabbit. Circulation, 105, 354-359.

McGregor, B., \& Antoni, M. H. (2009). Psychological intervention and health outcomes among women treated for breast cancer: A review of stress pathways and biological mediators. Brain, Behavior, and Immunity, 23, 159-166.

McIntosh, R. C., Antoni, M., Carrico, A., Duran, R., Hurwitz, B. E., Ironson, G., et al. (2017). Change in urinary cortisol excretion mediates the effect of angry/hostile mood on 9 month diastolic blood pressure in HIV+ adults. Journal of Behavioral Medicine, 40, 620-630.

McIntosh, R. C., Ironson, G., Antoni, M., Kumar, M., Fletcher, M. A., \& Schneiderman, N. (2014). Alexithymia is linked to neurocognitive, psychological, neuroendocrine, and immune dysfunction in persons living with HIV. Brain, Behavior, and Immunity, 36, $165-175$.

Mendes de Leon, C. F., Powell, L. H., \& Kaplan, B. (1991). Change in coronary-prone behaviors in the recurrent coronary prevention project. Psychosomatic Medicine, 53, 407-419.

Miller, G. E., Cohen, S., \& Ritchey, A. K. (2002). Chronic psychological stress and the regulation of pro-inflammatory cytokines: A glucocorticoid-resistance model. Health Psychology, 21, 531-541.

Mocroft, A., Ledergerber, B., Katlama, C., Kirk, O., Reiss, P., d'Arminio Monforte, A., et al. (2003). Decline in the AIDS and death rates in the EuroSIDA study: An observational study. The Lancet, 362, 22-29.

Mottillo, S., Filion, K. B., Genest, J., Joseph, L., Pilote, L., Poirier, P., et al. (2010). The metabolic syndrome and cardiovascular risk: A systematic review and meta-analysis. Journal of the American College of Cardiology, 56, 1113-1132.

Mulder, C., Antoni, M., Duivenvoorden, H., Kauffmann, R., \& Goodkin, K. (1995a). Active confrontational coping predicts decreased clinical progression over a one-year period in HIVinfected homosexual men. Journal of Psychosomatic Research, 39, 957-965.

Mulder, C., Antoni, M., Emmelkamp, P., Veugelers, P., Sandfort, T. G., Van de Vijver, F., et al. (1995b). Psychosocial group intervention and the rate of decline of immunological parameters in asymptomatic HIV-infected homosexual men. Psychotherapy and Psychosomatics, 63, 185-192.

Nausheen, B., Gidron, Y., Peveler, R., \& Moss-Morris, R. (2009). Social support and cancer progression: A systematic review. Journal of Psychosomatic Research, 67, 403-415.

Newell, S., Sanson-Fisher, R., \& Savolainen, N. (2002). Systematic review of psychological therapies for cancer patients: Overview and recommendations for future research. JNCI: Journal of the National Cancer Institute, 94, 558-584.

Noone, A. M., Howlader, N., Krapcho, M., Miller, D., Brest, A., Yu, M., Ruh, L. J., Tatalovich, Z., Mariotto, A., Lewis, D. R., Chen, H. S., Feuer, E. J., Cronin, K. A. (eds).(2018). SEER Cancer Statistics Review, 1975-2015, National Cancer Institute. Bethesda, MD. https://seer.cancer.gov/csr/1975_2015/. Based on November 2017 SEER data submission, posted to the SEER web site, April 2018

Oh, P. J., Shin, S. R., Ahn, H. S., \& Kim, H. J. (2016). Meta-analysis of psychosocial interventions on survival time in patients with cancer. Psychology and Health, 31, 396-419.

Orth-Gomér, K., Schneiderman, N., Wang, H., Walldin, C., Bloom, M., \& Jernberg, T. (2009). Stress reduction prolongs life in women with coronary disease: The Stockholm Women's Intervention Trial for Coronary Heart Disease (SWITCHD). Circulation: Cardiovascular Quality and Outcomes, 2, 25-32.

Page-Shafer, K., Delorenze, G. N., Satariano, W. A., \& Winkelstein, W. (1996). Comorbidity and survival in HIV-infected men in the San Francisco Men's Health Survey. Annals of Epidemiology, 6, 420-430.

Paredes, J., Szeto, A., Levine, J. E., Zaias, J., Gonzales, J. A., Mendez, A. J., et al. (2006). Social experience influences hypothalamic oxytocin in the WHHL rabbit. Psychoneuroendocrinology, 31, 1062-1075.

Parhoon, H., Masomzadeh, K., Moradi, A., \& Mirmotahari, M. (2017). Effectiveness of mindfulness-based Stress reduction (MBSR) on anxiety, depression and post-traumatic stress 
disorder symptoms in patients with HIV/AIDS. International Journal of Behavioral Sciences, 10, 129-134.

Parruti, G., Vadini, F., Sozio, F., Mazzott, E., Ursini, T., Polill, E., et al. (2013). Psychological factors, including alexithymia, in the prediction of cardiovascular risk in HIV infected patients: Results of a cohort study. PLOS ONE, 8, e54555.

Patterson, T. L., Shaw, W. S., Semple, S. J., Cherner, M., McCutchan, J. A., Atkinson, J. H., et al. (1996). Relationship of psychosocial factors to HIV disease progression. Annals of Behavioral Medicine, 18, 30.

Pellowski, J. A., \& Kalichman, S. C. (2012). Recent advances (2011-2012) in technology-delivered interventions for people living with HIV. Current HIV/AIDS Reports, 9, 326-334.

Pence, B. W., Mills, J. C., Bengtson, A. M., Gaynes, B. N., Breger, T. L., Cook, R. L., et al. (2018). Association of increased chronicity of depression with HIV appointment attendance, treatment failure, and mortality among HIV-infected adults in the United States. JAMA Psychiatry, 75, 379-385.

Perry, S., Fishman, B., Jacobsberg, L., \& Frances, A. (1992). Relationships over 1 year between lymphocyte subsets and psychosocial variables among adults with infection by human immunodeficiency virus. Archives of General Psychiatry, 49, 396-401.

Phillips, K. M., Antoni, M. H., Carver, C. S., Lechner, S. C., Penedo, F. J., McCullough, M. E., et al. (2011). Stress management skills and reductions in serum cortisol across the year after surgery for non-metastatic breast cancer. Cognitive Therapy and Research, 35, 595-600.

Phillips, K. M., Antoni, M. H., Lechner, S. C., Blomberg, B. B., Llabre, M., Avisar, E., et al. (2008). Stress management intervention reduces serum cortisol and increases relaxation during treatment for non-metastatic breast cancer. Psychosomatic Medicine, 70, 1044-1049.

Pinquart, M., \& Duberstein, P. (2010). Associations of social networks with cancer mortality: A meta-analysis. Critical Reviews in Oncology and Hematology, 75, 122-137.

Quiles, N. N., Ciccolo, J. T., \& Garber, C. E. (2017). Association between physical activity, depression, and diabetes in urbandwelling people living with HIV. Journal of the Association of Nurses in AIDS Care, 28, 838-848.

Rabkin, J. G., Williams, J. B., Remien, R. H., Goetz, R., Kertzner, R., \& Gorman, J. M. (1991). Depression, distress, lymphocyte subsets, and human immunodeficiency virus symptoms on two occasions in HIV-positive homosexual men. Archives of General Psychiatry, 48, 111-119.

Robinson, F. P., Mathews, H. L., \& Witek-Janusek, L. (2003). Psycho-endocrine-immune response to mindfulness-based stress reduction in individuals infected with the human immunodeficiency virus: A quasi experimental study. The Journal of Alternative \& Complementary Medicine, 9, 683-694.

Rodriguez-Penney, A. T., Ludicello, J. E., Riggs, P. K., Doyle, K., Ellis, R. J., Letendre, S. L., et al. (2013). Co-morbidities in persons infected with HIV: Increased burden with older age and negative effects on health-related quality of life. AIDS Patient Care and STDs, 27, 5-16.

Rosen, R. K., McGarrity, L. A., Salmoirago-Blotcher, E., Rich, C., Rana, A., \& Carey, M. P. (2017). Telephone-delivered mindfulness training for people living with HIV: A qualitative $360^{\circ}$ inquiry. AIDS and Behavior, 21, 3194-3201.

Rouet, F., Ekouevi, D. K., Chaix, M.-L., Burgard, M., Inwoley, A., Tony, T. D. A., et al. (2005). Transfer and evaluation of an automated, low-cost real-time reverse transcription-PCR test for diagnosis and monitoring of human immunodeficiency virus type 1 infection in a West African resource-limited setting. Journal of Clinical Microbiology, 43, 2709-2717.
Rubtsova, A. A., Kempf, M.-C., Taylor, T. N., Konkle-Parker, D., Wingood, G. M., \& Holstad, M. M. (2017). Healthy aging in older women living with HIV infection: A systematic review of psychosocial factors. Current HIV/AIDS Reports, 14, 17-30.

Sankar, A., Nevedal, A., Neufeld, S., Berry, R., \& Luborsky, M. (2011). What do we know about older adults and HIV? A review of social and behavioral literature. AIDS Care, 23, 1187-1207.

Schneiderman, N. (1983). Pathophysiology in animals. In T. M. Dembroski, T. H. Schmidt, \& G. Blümhen (Eds.), Biobehavioral bases of coronary heart disease (pp. 304-364). Basel: Karger.

Schneiderman, N., Saab, P. G., Catellier, D. J., Powell, L. H., DeBusk, R. F., Williams, R. B., et al. (2004). Psychosocial treatment within gender by ethnicity subgroups in the Enhancing Recovery in Coronary Heart Disease (ENRICHD) Clinical Trial. Psychosomatic Medicine, 66, 475-483.

Schrepf, A., Thaker, P., Goodheart, M. J., Bender, D., Slavich, G., Dahmoush, L., et al. (2015). Diurnal cortisol and survival in epithelial ovarian cancer. Psychoneuroendocrinology, 53, 256-267.

Schwartz, R. M., Mansoor, A., Wilson, T. E., Anastos, K., EversonRose, S. A., Golub, E. T., et al. (2012). Chronic depressive symptoms and Framingham coronary risk in HIV-infected and HIV-uninfected women. AIDS Care, 24, 394-403.

Scott-Sheldon, L. A., Kalichman, S. C., Carey, M. P., \& Fielder, R. L. (2008). Stress management interventions for HIV+ adults: A meta-analysis of randomized controlled trials, 1989 to 2006. Health Psychology, 27, 129.

Selye, H. (1956). The stress of life. New York: McGraw-Hill.

SeyedAlinaghi, S., Jam, S., Foroughi, M., Imani, A., Mohraz, M., Djavid, G. E., et al. (2012). Randomized controlled trial of mindfulness-based stress reduction delivered to human immunodeficiency virus-positive patients in Iran: Effects on CD4+ T lymphocyte count and medical and psychological symptoms. Psychosomatic Medicine, 74, 620-627.

Shippy, R. A., \& Karpiak, S. E. (2005). The aging HIV/AIDS population: Fragile social networks. Aging \& Mental Health, 9, 246-254.

Sloan, E. K., Pricemen, S., Cox, B. F., Yu, S., Pimentel, M., Tangkanangnukul, V., et al. (2010). The sympathetic nervous system induces a metastatic switch in primary breast cancer. Cancer Research, 70, 7042-7052.

Smith, P. J., Blumenthal, J. A., Babyak, M. A., Hoffman, B. M., Doraiswamy, P. M., Waugh, R., et al. (2007). Cerebrovascular risk factors, vascular disease, and neuropsychological outcomes in adults with major depression. Psychosomatic Medicine, 69, 578-586.

Smith, P. J., Blumenthal, J. A., Babyak, M. A., Watkins, L. L., Hinderliter, B. M., Hoffman, B. M., et al. (2010). Cerebrovascular risk factors and cerebral hyperintensities among middleaged and older adults with major depression. The American Journal of Geriatric Psychiatry, 18, 848-852.

Smith, P. J., Blumenthal, J. A., Hinderliter, A. L., Watkins, L. L., Hoffman, B. M., \& Sherwood, A. (2018). Microvascular endothelial function and neurocognition among adults with major depressive disorder. The American Journal of Geriatric Psychiatry, 26, 1061-1069.

Solano, L., Costa, M., Salvati, S., Coda, R., Aiuti, F., Mezzaroma, I., et al. (1993). Psychosocial factors and clinical evolution in HIV1 infection: A longitudinal study. Journal of Psychosomatic Research, 37, 39-51.

Spencer, S., Lehman, J., Wynings, C., Arena, P., Carver, C. S., Antoni, M. H., et al. (1999). Concerns about breast cancer and relations to psychosocial well-being in a multi-ethnic sample of early stage patients. Health Psychology, 18, 159-169. 
Spiegel, D., Bloom, J. R., Kraemer, H. C., \& Gottheil, E. (1989). Effect of psychosocial treatment on survival of patients with metastatic breast cancer. Lancet, 2, 888-891.

Spiegel, D., Butler, L. D., Giese-Davis, J., Koopman, C., Miller, E., DiMiceli, S., et al. (2007). Effects of supportive-expressive group therapy on survival of patients with metastatic breast cancer: A randomized prospective trial. Cancer, 110, 1130.

Stagl, J. M., Lechner, S. C., Carver, C. S., Bouchard, L. C., Gudenkauf, L. M., Jutagir, D. R., et al. (2015). A randomized controlled trial of cognitive-behavioral stress management in breast cancer: Survival and recurrence at 11-year follow-up. Breast Cancer Research Treatment, 154, 319-328.

Stanton, A. L. (2006). Psychosocial concerns and interventions for cancer survivors. Journal of Clinical Oncology, 24, 5132-5173.

Steel, J., Geller, D., Gamblin, T., Olek, M., \& Carr, B. (2007). Depression, immunity, and survival in patients with hepatobilliary carcinoma. Journal of Clinical Oncology, 25, 2397-2405.

Steginga, S., Lynch, B., Hawkes, A., Dunn, J., \& Aitken, J. (2009). Antecedents of domain-specific quality of life after colorectal cancer. Psychooncology, 18, 216-220.

Szeto, A., Nation, D. A., Mendez, A. J., Dominguez-Bendala, J., Brooks, L. G., Schneiderman, N., et al. (2008). Oxytocin attenuates NADPH-department superoxide activity and IL-6 secretion in macrophages and vascular cells. American Journal of Physiology, Endocrinology and Metabolism, 295, E1495E1501.

Talley, A., Molix, L., Schlegel, R. J., \& Bettencourt, A. (2010). The influence of breast cancer survivors' perceived partner social support and need satisfaction on depressive symptoms: A longitudinal analysis. Psychology \& Health, 25, 433-449.

Taylor, S. E., Kemeny, M. E., Reed, G. M., Bower, J. E., \& Gruenewald, T. L. (2000). Psychological resources, positive illusions, and health. American Psychologist, 55, 99.

Temel, J. S., Greer, J. A., Muzikansky, A., Gallagher, E. R., Admane, S., Jackson, V. A., et al. (2010). Early palliative care for patients with metastatic non-small-cell lung cancer. The New England Journal of Medicine, 363, 733-742.

Theorell, T., Blomkvist, V., Jonsson, H., Schulman, S., Berntorp, E., \& Stigendal, L. (1995). Social support and the development of immune function in human immunodeficiency virus infection. Psychosomatic Medicine, 57, 32-36.

Thornton, L., Andersen, B., \& Carson, W. (2008). Immune, endocrine, and behavioral precursors to breast cancer recurrence: A case-control analysis. Cancer Immunology and Immunotherapy, 57, 1471-1481.

Thornton, S., Troop, M., Burgess, A., Button, J., Goodall, R., Flynn, R., et al. (2000). The relationship of psychological variables and disease progression among long-term HIV-infected men. International Journal of STD and AIDS, 11, 734-742.

Tuomilehto, J., Lindstrom, J., Eriksson, J. G., Valle, T. T., Hamalainen, H., Ilanne-Parikka, P., et al. (2001). Prevention of type 2 diabetes mellitus by changes in lifestyle among subjects with impaired glucose tolerance. New England Journal of Medicine, 344, 1343-1350.

Vadini, F., Sozio, F., Mazzotta, E., Agostinone, C., Ursini, T., Agostinone, A., et al. (2010). Alexithymia, an impairment of emotional cognitive processing, is a candidate risk factor for carotid artery plaque formation in HIV-infected patients. Journal of the International AIDS Society, 13, P70.

Vassend, O., \& Eskild, A. (1998). Psychological distress, coping, and disease progression in HIV-positive homosexual men. Journal of Health Psychology, 3, 243-257.

Vassend, O., Eskld, A., \& Halvorsen, R. (1997). Negative affectivity, coping, immune status, and disease progression in HIV infected individuals. Psychology and Health, 12, 375-388.

Villes, V., Spire, B., Lewden, C., Perronne, C., Besnier, J.-M., Garré, M., et al. (2007). The effect of depressive symptoms at ART initiation on HIV clinical progression and mortality: Implications in clinical practice. Antiviral Therapy, 12, 1067.

Watson, S. L., Shively, C. A., Kaplan, J. R., \& Line, S. W. (1998). Effects of chronic social separation on cardiovascular disease risk factors in female cynomolgus monkeys. Atherosclerosis, 137, 259-266.

Weihs, K. L., Enright, T. M., \& Simmens, S. J. (2008). Close relationships and emotional processing predict decreased mortality in women with breast cancer: Preliminary evidence. Psychosomatic Medicine, 70, 117-124. https://doi.org/10.1097/ PSY.0b013e31815c25cf.

Wenzel, L., DeAlba, I., Habbal, R., Kluhsman, B., Fairclough, D., Krebs, L., et al. (2005). Quality of life in long-term cervical cancer survivors. Gynecological Oncology, 97, 310-317.

White, J. R., Chang, C.-C. H., So-Armah, K. A., Stewart, J. C., Gupta, S. K., Butt, A. A., et al. (2015). Depression and HIV infection are risk factors for incident heart failure among veterans: Veterans aging cohort study. Circulation, 114, 014443.

Wimberly, S. R., Carver, C. S., Laurenceau, J. P., Harris, S. D., \& Antoni, M. H. (2005). Perceived partner reactions to diagnosis and treatment of breast cancer: Impact on psychosocial and psychosexual adjustment. Journal of Consulting and Clinical Psychology, 73, 300-311.

Wing, R. R., Bahnson, J. L., Bray, G. A., Clark, J. M., Coday, M., Egan, C., et al. (2010). Long-term effects of a lifestyle intervention on weight and cardiovascular risk factors in individuals with type 2 diabetes mellitus [Look AHEAD Trial]. Archives of Internal Medicine, 170, 1566-1575.

Wing, R. R., Bolin, P., Brancati, F. L., Bray, G. A., Clark, J. M., Coday, M., et al. (2013). Cardiovascular effects of lifestyle intervention in type 2 diabetes. New England Journal of Medicine, 369, 145-154.

Young, J., De Geest, S., Spirig, R., Flepp, M., Rickenbach, M., Furrer, H., et al. (2004). Stable partnership and progression to AIDS or death in HIV infected patients receiving highly active antiretroviral therapy: Swiss HIV cohort study. BMJ, 328, 15.

Yun, L. W., Maravi, M., Kobayashi, J. S., Barton, P. L., \& Davidson, A. J. (2005). Antidepressant treatment improves adherence to antiretroviral therapy among depressed HIV-infected patients. JAIDS Journal of Acquired Immune Deficiency Syndromes, 38, 432-438.

Publisher's Note Springer Nature remains neutral with regard to jurisdictional claims in published maps and institutional affiliations. 